\title{
Research data: private property or public good?
}

\section{Do scientists have a right to protect preliminary research findings from outside scrutiny? David Dickson reports on a growing controversy}

LAST year, when a New York public interest group needed help in analysing the results of a national survey of infantfeeding practices, it turned to the Center for Disease Control (CDC) in Atlanta for assistance in putting the data through a computer.

CDC agreed to cooperate, and the data were duly stored. But being a public agency, its records are open to public scrutiny under the Freedom of Information Act. And CDC subsequently received a request from Abbott Laboratories and Mead-Johnson (a subsidiary of Bristol Myers), for access to the survey data. Ross Laboratories (a subsidiary of Abbott) and Mead-Johnson have been criticised over the nutritional value of their baby foods.

In January an administrative law judge upheld CDC's view that it lacks the legal power to deny the companies access to the data. And the centre is now being taken to court by the public interest group, the Interfaith Center on Corporate Responsibility (ICCR) to protect its data until it has been able to analyse the results and publish its own conclusions.

Two factors are complicating the increasingly sensitive problem of whether a research worker has any moral or legal rights over preliminary research data. The first is the growing economic importance of such data, for example where animal studies or clinical trials determine whether a new drug can be licensed. The second is the public's demand for information on substances likely to affect lives.

In the case of privately funded research, companies retain the right to withold all test data supporting claims of efficacy or safety, on the grounds that these are trade secrets whose publication might have an economic impact on the product.

Moreover the Supreme Court, in a case brought by a group of physicians demanding access to data criticising the efficacy of an anti-diabetes drug, ruled last month that the raw data generated by a private laboratory under contract to the National Institutes of Health do not constitute an 'agency record' within the meaning of the FoI Act.

The main problem concerns the type of access permitted to federally-conducted research: in the case of clinical trials, for example, it can be argued that the disclosure of partial results before the trial is completed may jeopardise the final outcome.

Spurred by such concerns, NIH is seeking exemption for such data from the
Freedom of Information Act. Initially it had proposed that both epidemiological studies and clinical trials should be exempt. But following various objections, it has now developed a more restricted proposal, namely that it will be possible to withhold from public disclosure 'trend data' until it has been completed and verified (individual medical records are already protected by law).

To counter the argument that, without access to information on the conduct of the trial, the public has no check on whether it is being carried out responsibly, NIH is also proposing that exemptions will only be allowed if explicit measures have been taken to assure patients' safety.

Not all critics are satisfied. Dr Sidney Wolfe of the Health Research Group for example, which has consistently attacked the secrecy surrounding drug tests, argues that the protection of patients and the integrity of the tests can only be guaranteed through the fullest possible disclosure.

"Research workers can have an incredible bias, which may not be in the best interests of participants or intended participants in a particular trial" he says. "In general the more people who have access to a given body of data, the better".

Others argue differently, not only supporting the pragmatic claim that upsetting a large-scale blind trial may be very expensive, but also suggesting that a research worker has a moral right to present the first interpretation of data he or she has collected.

"This has been an underlying postulate of scientific conduct which is generally accepted" says Professor John Edsall of Harvard University, chairman of the

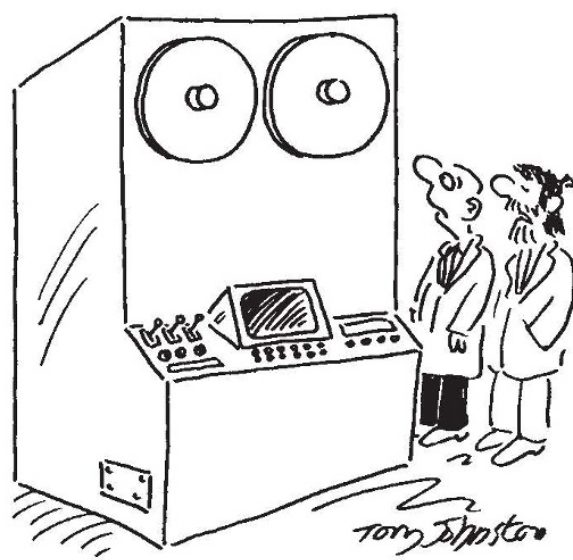

"What makes you think the computer will be biased against processed baby foods?"
American Association for the Advancement of Science's Committee on Scientific Freedom and Responsibility.

Some also fear that, if a scientist's research notes are not protected from public scrutiny, he or she may be tempted to destroy them once the data has appeared in its final form.

The NIH's proposal that its clinical trials may, in given circumstances, be exempt from the full provisions of the FoI Act have been closely scrutinised by the NIH's Ethics Advisory Board. And following lengthy discussion of the revised proposal at a meeting of the board two weeks ago, it seems that the board will be prepared to support the proposal when it meets again in April.

It has been less convinced by arguments that information provided by private hospitals to $\mathrm{CDC}$ - for example on problems of infection in hospital wards be kept secret for fear that publicity could generate undue public concern.

CDC had argued that, without some guarantee of anonymity, hospitals may be reluctant to come to them for assistance. But board members expressed the opinion that, although exemptions might be appropriate in some circumstances, this type of information was likely to have already reached the public domain by other routes.

And then there is the case of the infant feeding survey results, private data whose presence in CDC's computers appears to have made it public.

Here the view that all information should be as open as possible conflicts directly with the claim that, particularly in such a sensitive area, those who have collected the data should be allowed to offer their interpretation before others try to refute it.

Indeed, in this case the two baby-food manufacturers concerned have already written to family practitioners suggesting weaknesses in the study, which was carried out to discover the extent to which lowerincome families use processed baby foods, and the nutritional implications.

ICCR claims that, since it collected the data - and has agreed eventually to make it available to anyone interested - it has a right to prevent its prior use by others. And it quotes in support the practice of the World Health Organisation, namely that research data received for analysis and processing "will not be released in incomplete form to any third party without permission from the research scientist who has collected the data".

It is now up to a court of law to decide what force the traditions of the research community hold against current legal definitions of the rights of access to the results of research. 